\title{
Wheat grass benefits
}

\section{Opinion}

Wheat Grass is nature's finest medicine. Many Herbal practitioners prefer intake of Wheatgrass powder or juice because of its many basic components and trace elements with immense healing capacity. It is a powerful concentrated liquid nutrient having immense benefits (Figure 1). Two ounces of wheat grass juice has the nutritional equivalent of five pounds of the best raw organic vegetables. As compared to Carrots, it has approx. twice the amount of Vitamin A and is higher in Vitamin $\mathrm{C}$ than oranges! It contains the full spectrum of $\mathrm{B}$ vitamins, as well as calcium, phosphorus, magnesium, sodium and potassium in a balanced ratio. Wheatgrass is a complete source of protein, supplying all of the essential amino acids, and more. It has about $20 \%$ of total calories coming from protein in the form of poly peptides, simpler and shorter chains of amino acids that are efficiently used in the blood stream and tissues.

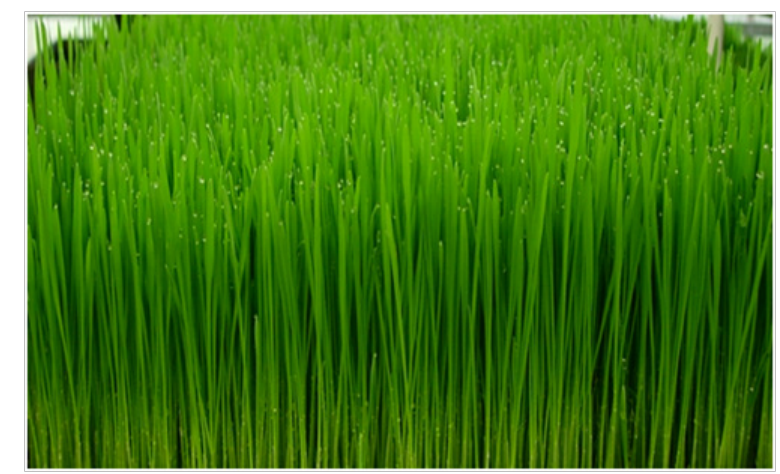

Figure I Wheat grass.

i. It is a living food and has bio-electricity if consumed fresh. This high vibration energy is literally the life force within the living juice. This resource of life-force energy can potentially unleash powerful renewing vibrations and greater connectivity to one's inner being.

ii. It also helps in preventing DNA destruction and from various ongoing effects of pre-mature aging and cellular breakdown.

iii. Many researches show that only living foods and juices can restore the electrical charge between the capillaries and the cell walls which boosts the immune system \& wheatgrass juice is the best among living juices.

iv. Wheatgrass possesses antibacterial activities which destroy the germs, even it is also useful in tuberculosis and intestinal disorders. It protects body from radiations, smoke of cigarette and vehicles.

v. In addition to flooding the body with therapeutic dosages of vitamins, minerals, antioxidants, enzymes, and phytonutrients, wheatgrass is also a powerful detoxifier, especially of the liver and blood. It helps neutralize toxins and environmental pollutants in the body and protect us from carcinogens, including Superoxide
Volume 3 Issue 5 - 2016

\author{
Baldeep Kour \\ Deep Ayurveda, India
}

\section{Oopen Access CrossMark}

Correspondence: Baldeep Kour, Deep Ayurveda, H.N. I6IA, Dasmesh Nagar, Sector-16, Kharar, Mohali, India, Tel 9216582020 , Email deepayurveda@gmail.com

Received: April 27, 2016 | Published: May 25, 2016

Disumates (SOD), that lessens the effects of radiation and digest toxins in the body.

vi. It is an effective full body cleanser also. As per the concept of Naturopathy, reason behind each and every disease or disorder is assumed due to the highly accumulated toxins inside the body. It due to the uncontrolled diet, lack of natural foods, fresh air, polluted water, pollutants, lack of exercise, mental stress, uncontrolled intake of pharmaceuticals, etc. Our body naturally expels out these toxicants but when it goes beyond the limits, and then there is no best way than Wheat Grass.

vii. Things need to be considered while consuming Wheat Grass juice:

viii. The wheatgrass juice must be consumed fresh - within fifteen minutes of juicing for the best results.

ix. The juice should always be taken on an empty stomach for the efficient absorption of the nutrients.

\section{Components of wheat grass $\&$ its benefits}

The main components found in the Wheat Grass are-

I. Vitamins - A,B,C \& E

II. Proteins \& Amino Acids

III. Enzymes

IV. Minerals - Calcium, Iron, Sodium, Zinc, Magnesium, Potassium \& Selenium

\section{Chlorophyll}

VI. Antioxidants

\section{The benefits of these components are}

Vitamin A: It is useful for eyes \& skin care. It cures night blindness, protects kidneys from stone formation, and prevents repetitive infections in ear, nose and throat. It is also useful for dry hairs, black round around the eyes $\&$ wrinkles on the skin. 
Vitamin B: Useful in digestive \& nervous sytem diseases, appetisis, beriberi, mouth infection, aging, insomnia, mental health, the Litriel from B-17 helps in healing of wounds.

Vitamin C: being a natural antibiotic, it helps in increasing immunity $\&$ sex disorders. It is also useful in the healing of wounds along with taking care of the health of teeth $\&$ gums.

Vitamin E: Useful in various degenerative diseases like cancer, sugar and helps in the activation of regeneration system. It metabolizes lipids, provides energy, promotes sperm formation and treats the problems of potency \& abortion.

\section{Wheat grass minerals}

Minerals are useful for the muscles and cells. It maintains Acid - Base balance. Uses of Wheat Grass minerals are-

Calcium: Useful of health of bones, in old age bone density, growth of child. Useful in body swelling, bleeding, blood circulation, disquiet, varicose veins etc.

Iron: Useful in blood formation in anemia, particularly in pregnancy, tiredness, sweating, laziness \& sleeplessness.

Sodium: Useful in digestion, body purification, maintaining acidbase balance \& kidney stone inhabitation.

Potassium: Useful in sleeplessness, high blood pressure, loss of memory, weakness, fearing, willingness of suicide, sex disorder, beauty problems and aging.

Magnesium: It keeps intestine and muscles healthy, useful in hepatitis, late month cycle, dysentery, and weakness of mind, teeth ache, smelling of stool, cold \& indigestion.

Zinc: It keeps hairs and prostate glands healthy.

Selenium: Useful in various kinds of cancer.

\section{Wheat grass enzymes}

There are various kinds of enzymes which are useful in various ways. It is a catalyst; it activates the functioning of the parts of the body.

\section{Wheat grass proteins and amino acids}

Proteins are important food ingredients on which generation of body cells and growth of body depends. Amino acids, plasma, hormones are formed. Muscle growth and power depends on protein.

Beside these there are also some of un-investigated unknown factors found in the Wheat Grass which are useful for human body.

\section{Wheat grass chlorophyll (most important component)}

It is one of the main \& most useful component of Wheat Grass having $70 \%$ occupation in it. The researchers assume that the Wheat
Grass chlorophyll has the power of sun \& that's why it is also called as a blood of grass. The Hemein from the hemoglobin and chlorophyll has many similarities. When freshly made into drink fresh wheatgrass juice, chlorophyll contains synthesized sunshine, plus the electric current necessary for the revitalization of the body. Chlorophyll can protect us from carcinogens like no other food or medicine can, it acts to strengthen the cells, detoxify the liver and blood stream and chemically neutralize the polluting elements themselves.

\section{Opinion of renowned doctors about wheat grass}

i. Noble prize winner for the research on RBCs of blood, Dr. Hans Fischer (German scientist in organic chemistry \& Medicines) proved that there are more similarities in human blood and plant chlorophyll. Dr. Hans and Dr. Latner in an experiment found out that Wheat Grass chlorophyll increases the RBCs in animals.

ii. Burcher says that chlorophyll is a concentrated sun power and regulates functions of heart, intestine, kidneys and lungs. It is blood purifier, antibacterial $\&$ also useful in stomach ulcers.

iii. The scientists Dr. Marisita \& Dr. Cono Hota say that chlorophyll is a good germicide and body deodorant. In his book "Chlorophyll - Natures Green Magic" he says- for pyorrhea, anemia, asthma, indigestion, acidity, joint pains can be cured by Wheat Grass chlorophyll.

\section{Looking for easy availability of wheat grass products?}

Wheat Grass in form of capsules is available at Deep Ayurveda clinics for easy $\&$ immediate use. There is no need for any extra effort now to find this nutrient at any unhygienic or unsafe place. Deep Ayurveda using only organic and genuine quality wheat grass as raw material to manufacturing wheat grass powder, capsules and Juices. You can also buy Wheat Grass capsules online by visiting the product page.

Your good health \& nutritional supplement is now just a click away from you.

\section{Acknowledgments}

None.

\section{Conflicts of interest}

Author declares there are no conflicts of interest.

\section{Funding}

None. 